\title{
Vascular plant species response to warming and elevated carbon dioxide in a boreal peatland
}

\author{
Mara McPartland ${ }^{1}$, Rebecca Montgomery ${ }^{1}$, Paul Hanson ${ }^{2}$, Jana Phillips ${ }^{2}$, Randy Kolka ${ }^{3}$, \\ and Brian Palik ${ }^{3}$ \\ ${ }^{1}$ University of Minnesota Twin Cities \\ ${ }^{2}$ Oak Ridge National Laboratory \\ ${ }^{3}$ USDA Forest Service
}

May 5, 2020

\begin{abstract}
The Spruce and Peatland Responses Under Changing Environments (SPRUCE) project is a warming and elevated carbon dioxide (CO2) experiment designed to test how peatland ecosystems will respond to climate change. Here, we report changes in the vascular plant community during the first five years of SPRUCE. We tracked species composition, diversity, and aboveground net primary production (ANPP) in chambers warmed at a wide range of temperatures $(+0,+2.25,+4.5,+6.75,+9 @ \mathrm{C})$, and two CO2 levels ( 400 [ambient] and 900 parts per million). We observed an increase in aboveground vascular plant biomass accumulation, due primarily to an increase in shrub abundances. Overall species diversity decreased substantially, likely due in part to shading by a denser shrub canopy. These results indicate an overall increase in NPP with warming, but highlight the importance of interactions between direct (warming) and indirect (competition) effects in determining how boreal ecosystems will respond to climate change.
\end{abstract}

\section{Hosted file}

McPartland_etal_MainBody.pdf available at https://authorea.com/users/307316/articles/438264vascular-plant-species-response-to-warming-and-elevated-carbon-dioxide-in-a-borealpeatland 


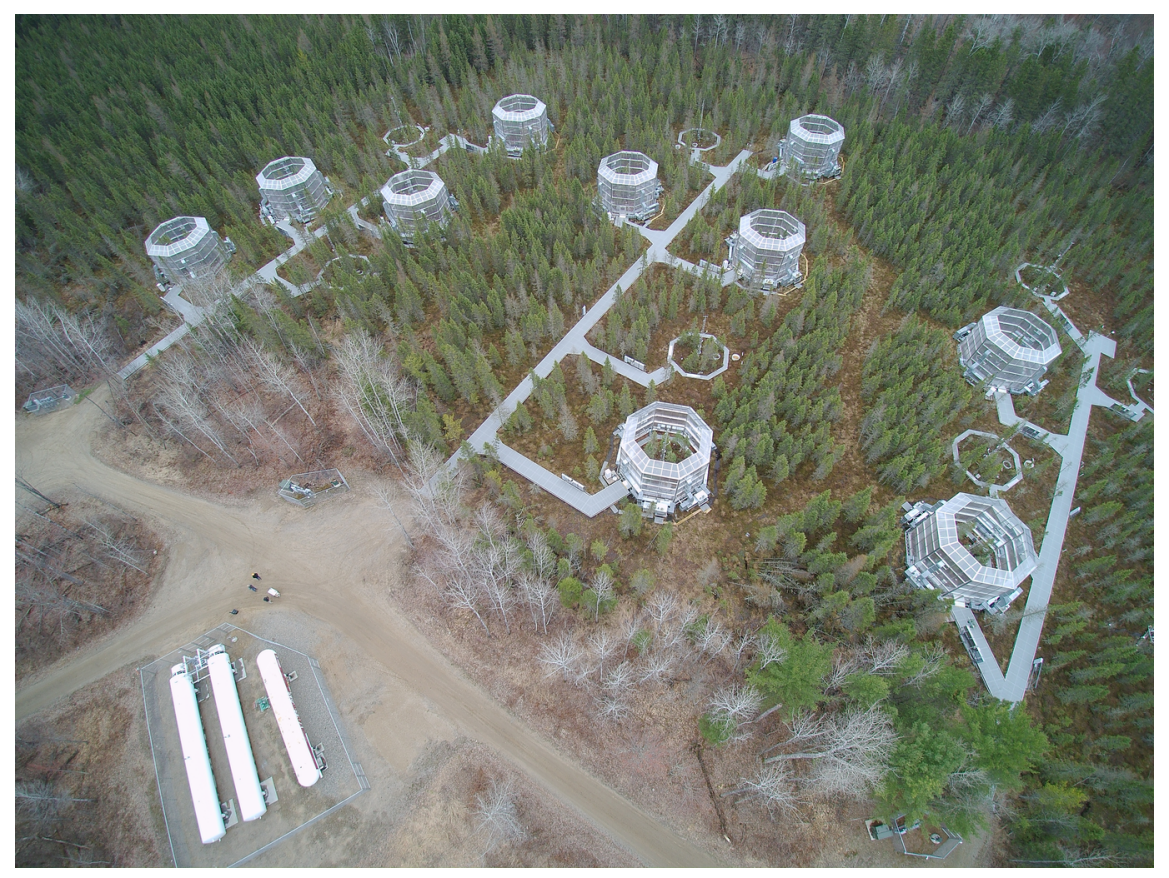

